\title{
Orta Kızılırmak Bölümündeki Seyfe Gölü Sulak Alanında Oluşan Toprakların Bazı Özelliklerinin İncelenmesi
}

\author{
Ahu Alev ABACI-BAYAR ${ }^{1^{*}(\mathbb{D})}$, Kadir YILMAZ ${ }^{2}$, Yusuf BAYAR ${ }^{3}$ (D) \\ ${ }^{1}$ Kırşehir Ahi Evran Üniversitesi, Ziraat Fakültesi, Peyzaj Mimarlığı Bölümü, Kırşehir, 40100 \\ ${ }^{2}$ Kahramanmaraş Sütçü İmam Üniversitesi, Ziraat Fakültesi, Toprak Bilimi ve Bitki Besleme Bölümü, \\ Kahramanmaraş, 46100 \\ ${ }^{1}$ Kırşehir Ahi Evran Üniversitesi, Ziraat Fakültesi, Bitki Koruma Bölümü, Kırşehir, 40100
}

Geliş / Received: 28/02/2020, Kabul / Accepted: 30/08/2020

\section{$\ddot{O} \mathbf{z}$}

Seyfe Gölü (Kırşehir, Türkiye) Orta Anadolu'da bulunan gerek coğrafi konum olarak gerekse sulak alan özelliği bakımından önemli bir statüye sahiptir. Kumlu- killi tın bünyeye sahip olan toprakların, hafif ve kuvvetli alkalin özellik gösterdiği, çok fazla tuzlu (15.7 dS m$\left.{ }^{-1}\right)$, çok fazla kireçli (516.6 $\left.\mathrm{g} \mathrm{kg}^{-1}\right)$ ve düşük organik maddeye (20.5 $\mathrm{g} \mathrm{kg}^{-1}$ ) sahip olduğu belirlenmiştir. Toprakların ıslak agregat stabilitesi ve kıvam limitleri (plastik sınırı, sıvı sınırı, plastik indeksi) değerlerinin, toprakların organik madde, toplam kireç ve kil miktarından önemli oranda etkilendiği belirlenmiştir. Yarayışlı P miktarının fazla (26.18 mg kg-1), Cu yeterli (1.19 mg kg-1), Mn çok az (3.06 mg kg-1), Zn ve Fe az (0.30 mg kg-1, $0.36 \mathrm{mg} \mathrm{kg}^{-1}$ ) olduğu belirlenmiştir. Topraklarda değişebilir katyon bakımından en fazla bulunan element $\mathrm{Na}$ iken bunu sırasıyla $\mathrm{Ca}, \mathrm{K}$ ve $\mathrm{Mg}$ takip etmiştir. Toprak alkaliliği açısından sorun yaratan sodyumun sıralamada önemli oranlarda bulunması, artan toplam tuzluluk ve kireç ile birlikte $\mathrm{pH}>8$ olması, araştırma alanının alkalilik ve tuzluluk yönünden takip edilmesinin gerektiğini ortaya çıkarmıştır.

Anahtar Kelimeler: Seyfe Gölü, sulak alan, toprak, alkalilik, tuzluluk

\section{Investigation of Some Properties of Soils in Seyfe Lake Wetland in Middle Kızılırmak Section}

\section{Abstract}

Seyfe Lake (Kirsehir, Turkey) situating in Central Anatolia has a critical role in terms of both its geographical location and wetlands characteristics. Sandy-clay-loam textured soils of the region were found to be light and strong alkaline, too salty $\left(15.7 \mathrm{dS} \mathrm{m} \mathrm{m}^{-1}\right)$, very calcareous $\left(516.6 \mathrm{~g} \mathrm{~kg}^{-1}\right)$ and low organic matter $\left(20.5 \mathrm{~g} \mathrm{~kg}^{-1}\right)$ content. It was determined that wet aggregate stability and consistency limits (plastic limit, liquid limit, plastic index) of the soils were significantly affected by organic matter, carbonate and clay contents. The availability of the nutrients of the soils were classified as high available $\mathrm{P}\left(26.18 \mathrm{mg} \mathrm{kg}^{-1}\right)$, sufficient $\mathrm{Cu}\left(1.19 \mathrm{mg} \mathrm{kg}^{-1}\right)$, very low Mn (3.06 mg kg-1), low $\mathrm{Zn}$ and $\mathrm{Fe}\left(0.30 \mathrm{mg} \mathrm{kg}^{-1}, 0.36 \mathrm{mg} \mathrm{kg}^{-1}\right)$. Sodium was prevalent in the exchangeable cations and followed by $\mathrm{Ca}, \mathrm{K}$ and $\mathrm{Mg}$, respectively. The fact that sodium, which causes problems in terms of soil alkalinity, has significant ratios in the ranking, $\mathrm{pH}>8$ with increased total salinity and high calcareous content has revealed that the research area should be followed in terms of alkalinity and salinity. 
Keywords: Seyfe Lake, wetland, soil, alkalinity, salinity

\section{Giriş}

Sulak alanlar, yeryüzünün en zengin ve en üretken ekosistemlerini oluşturmaktadır. $\mathrm{Bu}$ alanlar bölge insanlarına ve ülkenin geneline geniş yelpazede hizmet veren oldukça karmaşık doğal sistemler olup yeryüzündeki hiçbir ekosistemle karşılaştırılmayacak ölçüde işlev ve değerlere sahiptir. Ramsar Sözleşmesi'ne (Sulak Alanların Korunmasına Dair Sözleşme) göre sulak alanlar; 'tabii veya suni, devamlı veya geçici, suları durgun veya akıntıl1, tatlı, acı veya tuzlu, denizlerin gelgit hareketlerinin çekilme devresinde altı metreyi geçmeyen derinlikleri kapsayan, başta su kuşları olmak üzere canlıların yaşama ortamı olarak önem taşıyan bütün sular, bataklık, sazlık ve turbiyeler ile bu alanların kıyı kenar çizgisinden itibaren kara tarafina doğru ekolojik açıdan suyla kaplı alanların tümü' olarak tanımlanmıştır (Anonim, 2014).

Türkiye sulak alanlar bakımından Bağımsız Devletler Topluluğu'ndan sonra Avrupa ve Ortadoğu'nun en zengin ülkeleri arasında yer almaktadır. Ülkemizin farklı topografik yapısı ve Batı Paleoarktik bölgedeki dört önemli kuş göç yolundan ikisinin Türkiye üzerinden geçmesi, ülkemiz sulak alanlarını diğer ülkelerin sulak alanlarından daha önemli kılmaktadır. Türkiye'nin sulak alanlarının karşısındaki en önemli tehditlerin başında su kaynaklarına yapılan müdahaleler, yer almaktadır. Tarımda kullanılan geleneksel sulama teknikleri ile su tüketimi artmakta, tarımsal kimyasallar yeraltı ve yüzey suları ile sularda kirlenmeye sebep olmaktadır. $\mathrm{Bu}$ tehditlerin boyutu sulak alanların yok olmasına kadar varacak sonuçlara neden olarak, sulak alanların doğrudan (balıkçılık, su temini, ulaşım vb.) ve dolaylı (iklim koşullarını düzenleme, sediment ve besin depolama, biyolojik çeşitliliği barındırma vb.) olarak sağladığ1 yararları ortadan kaldırmaktadır. $\mathrm{Bu}$ denli önemli olan sulak alanların kurutularak organik madde ayrışmasına neden olunması, besin akışı ve döngülerini etkileyerek karbon bakımından küresel 1sınmayı olumsuz etkilediği birçok araştırmacı tarafından ortaya konulmuştur (Moreno-Casasola vd., 2009; Junk vd., 2006).

Türkiye'de yaklaşık 1.5 milyon hektar alanda tuzluluk ve alkalilik sorunu bulunmakta ve toprakların tuzlulaşmasında ve alkalileşmesinde sulama, drenaj, toprak özellikleri, fizyografya ve iklim etmenleri gibi faktörler oldukça önemli olup (Ekmekçi vd., 2005); tuzluluk, alkalilik ve yüzeyde göllenme 'Sessiz düşman' olarak tanımlanmaktadır (Kanber vd., 2005). İç Anadolu Bölgesinde tuzlu ve jipsli litolojik formasyonlar yaygındır (Seymen, 1982; Kara, 1991; Çelik, 2002). Özellikle kurak ve yarı kurak iklim bölgelerinde düz veya düze yakın eğime sahip olan havzalardaki topraklarda drenaj yetersizliğinde kapilarite ile tuzların taşınması (Karaoğlu ve Yalçın, 2018), sulak alanların kurutulması ile aşırı sıcaklık şartlarında jipsli minerallerin toprak yüzeyinde tuz konsantrasyonunu arttırmas1 (Zor ve Şengün, 2002), tuzlu ve alkali topraktaki anyon ve katyonların $\left(\mathrm{Cl}^{-}, \mathrm{SO}_{4}^{-}\right.$, $\mathrm{Na}, \mathrm{Ca}, \mathrm{K}, \mathrm{Mg}$ ) artması ile tarımsal kullanıma açılan toprakların kimyasal özelliklerinde birçok değişiklikler meydana gelmektedir (Sar1 vd., 2000). Alkalilik sorunu bulunan arazilerde toprak yüzeyinde sık sık yaşanan su göllenmesi, buharlaşmanın yağıştan yüksek olduğu arazilerde kalın ve geçirimsiz kabuk tabakası oluşumuna neden olmaktadır (Budak ve Günal, 2015). 
Ulusal ve uluslararası öneme sahip olan Seyfe Gölü, Türkiye için özel bir yer olarak kabul edilmektedir. Sahip olduğu sığ su alanları, bataklıklar, sulak çayırlar ve bozkır alanları ülkemiz için önemli sulak alanlardan biri olmasında önemli bir etkendir. $\mathrm{Bu}$ özelliklere ek olarak sahip olduğu adacıklarıyla göçmen kuşlara güvenli bir kuluçka ortamı sağlaması da önemli olup 'Birinci Derece Doğa Koruma Alanı', 'Doğal Rezerv Alanı' ve Ramsar Sözleşmesi’ne dahil edilmesi ile uluslararası öneme sahip bir sulak alandır (Erdem, 2005; Çiftçi, 2013).

$\mathrm{Bu}$ çalışmada, şiddetli kuraklığın yoğun olarak hissedildiği göl çevresindeki topraklarda bazı fiziksel ve kimyasal özellikler belirlenmiş, topraklardaki tuzluluk ve alkalilik problemi incelenmiştir. Alanda daha çok hidrojeoloji ve su kalitesi çalışmaları yapılmıştır (Erguvanlı 1959; Çelik ve Yıldırım, 2006). Toprak özellikleri ile ilgili çalışma ve araştırmaların yeterli olmadığ1 görülmüştür. Ülkemizin önemli sulak alanlarından olan Seyfe Gölü'nün korunması ve planlanması yönündeki çabalar artarak devam etmektedir. $\mathrm{Bu}$ çalışma, yapılan ve çapılacak olan çabalara anlamlı katk1 sunması açısından önemlidir. Seyfe Gölü sulak alanında oluşan toprakların analiz değerlendirmelerinin, daha sonra yapılacak birçok bilimsel ve sosyal çalışmalara kaynak teşkil edebilecektir.

\section{Materyal ve Metot}

\section{1. Çalışma alanı}

Araştırma alanı (Seyfe Gölü), Orta Kızılırmak Bölümü'nde Kırşehir'in Mucur ilçesinin kuzeyinde yer alan kapalı bir havzada bulunan tektonik kökenli doğal bir sulak alan olduğu için kullanım şeklinden dolayı tuzludur. Göl alanı 1560 ha iken geçici bataklık alanı 6300 ha' dır ve deniz seviyesinden yüksekliği ortalama 1000-1100 m'dir. Çizelge 1 incelendiğinde $4.4 \mathrm{~mm}$ yağışla Ağustos ayı en kurak ay olurken, 51.5 mm yağış miktarı ile en fazla yağış Aralık ayında görülmektedir.

\begin{tabular}{|c|c|c|c|c|}
\hline \multirow[t]{2}{*}{$\begin{array}{l}\text { Aylık } \\
\text { ortalama } \\
\text { değerler }\end{array}$} & $\begin{array}{l}\text { Ortalama } \\
\text { sicaklık }\end{array}$ & $\begin{array}{l}\text { Maksimum } \\
\text { sicaklık }\end{array}$ & $\begin{array}{l}\text { Minimum } \\
\text { sicaklık }\end{array}$ & $\begin{array}{l}\text { Toplam } \\
\text { Yağış } \\
\text { Ortalaması }\end{array}$ \\
\hline & ${ }^{\circ} \mathrm{C}$ & ${ }^{\circ} \mathrm{C}$ & ${ }^{\circ} \mathrm{C}$ & $\mathrm{mm}$ \\
\hline Ocak & 0.2 & 4.1 & -3.7 & 49.0 \\
\hline Şubat & 1.9 & 6.4 & -2.6 & 38.6 \\
\hline Mart & 5.5 & 11.2 & -0.1 & 39.1 \\
\hline Nisan & 10.4 & 16.7 & 4.1 & 44.2 \\
\hline May1s & 14.6 & 21.3 & 7.9 & 47.2 \\
\hline Haziran & 18.3 & 25.7 & 11.4 & 35.5 \\
\hline Temmuz & 21.9 & 29.3 & 14.6 & 7.5 \\
\hline Ağustos & 21.8 & 29.3 & 14.4 & 4.4 \\
\hline Eylül & 17.9 & 25.5 & 10.4 & 12.6 \\
\hline Ekim & 12.5 & 19.3 & 5.8 & 26.5 \\
\hline Kasım & 7.1 & 12.7 & 1.6 & 39.3 \\
\hline Aralık & 2.7 & 6.6 & -1.1 & 51.5 \\
\hline
\end{tabular}

Göl ve çevresinde bataklığa ve tuzluluğa toleranslı halofitik (tuzcul), saf step ve çayır vejetasyonu bulunmaktadır. Gölün kurumasının ardından alana yayılan tuz oranının toprak üzerinde birikmesi step vejetasyonunu ve halofitik vejetasyonunu tehdit etmektedir (Eyüboğlu, 1995; Çeşmeci, 2010). Göl çevresinde metamorfik, evaporit ve karbonat kayaları bulunmakta; göl merkezine doğru, $\mathrm{Na} / \mathrm{Ca}$ oranı artmakta ve jips, halit+tenardit mineralleri artarken kalsit azalmaktadır. Kenarda kalsit, orta ve iç zonda jips ve merkezde ise halit+tenardit bulunmasıyla halka şeklinde bir dağılım görülmekte; sedimanlarında kalsit ve jips mineralleri, birbirlerinin yerini 
alabilmektedir (Önalgil, 2013). Havza toprakları, organik maddece fakir alüvyal, çok fazla kireçli hidromorfik, çok tuzlu ve alkali halomorfik topraklardan oluşmakta; topraklar zayıf drenajlı olup, $\mathrm{NaCl}$ ve $\mathrm{Na}_{2} \mathrm{SO}_{4}$ bitki yetişmesini büyük oranda engellemektedir (Çiftçi, 2013). Çalışma alanının jeolojik haritası Şekil 1'de, örnekleme yapılan alanın haritası Şekil 2'de verilmiştir.

\subsection{Metot}

Çalışma alanınında içinde yer aldığı Kırşehir Karasal İç Anadolu (KİAN) yağış rejiminde yer almakta ve bu rejim orta yağışl1, soğuk bir ilkbahar, kış ve az yağışlı sıcak bir yaz mevsimi ile birlikte yarı-kurak ve kurak-yarı nemli bozkır olarak tanımlanmaktadır (Türkeş, 1996, 2007). Bundan dolayı toprak örneklemesi yağışın az olduğu sicak yaz mevsiminde 2017 yılında yapılmıştır. Alanı temsil edecek şekilde, göl aynası enine kesitinden 0-30 cm derinliğinden 22 adet toprak örneği alınmış ve örnekleme poşetine konularak etiketlenmiştir.

Topraklar laboratuvar ortamında hava kurusu ile kurutulup, $2 \mathrm{~mm}$ ' lik elekten geçirilerek analize hazır hale getirilmiştir (Jackson, 1962). Topraklarda fiziksel ve kimyasal analizler 2 tekerrürlü olarak yapılmıştır. Saturasyon yüzdesi, kolloid yüzey alanlarının su ile doygun hale getirilmesi ile (Demiralay, 1993); $\mathrm{pH}$ ve toplam tuzluluk tayinleri, saturasyon çamurunda (Black, 1965; Tüzüner,1990); organik madde, modifiye edilmiş Walkey-Black metodu ile (Nelson ve Sommers, 1996); toplam kireç, Scheibler kalsimetresi ile (Gülçur, 1974); tekstür, Bouyoucos hidrometresi yöntemiyle (Bouyoucos, 1951) yapılmıştır. Yarayışlı fosfor, toprakların sodyum bikarbonat $\left(\mathrm{pH}: 8.5, \quad 0.5 \quad \mathrm{~N} \quad \mathrm{NaHCO}_{3}\right)$ ile ekstrakte edilmesiyle (Olsen vd., 1954); makro elementler ( $\mathrm{K}, \mathrm{Mg}, \mathrm{Na}, \mathrm{Ca}$ ), amonyum asetat (pH:7, $\left.1 \quad \mathrm{~N} \quad \mathrm{NH}_{4} \mathrm{OAc}\right)$ ile ekstrakte edilmesiyle (Helmke ve Sparks, 1996); alınabilir mikro elementler ( $\mathrm{Fe}, \mathrm{Cu}, \mathrm{Zn}, \mathrm{Mn}$ ), dietilentriaminpenta asetik asit ekstraksiyon (DTPA) (0.005 M DTPA + $0.01 \mathrm{M} \mathrm{CaCl}_{2}+$ $0.1 \mathrm{M}$ TEA) yöntemine göre ekstrakte edilmesiyle çözelti fazına geçen elementler AAS (Atomik Absorpsiyon Spektrometre) cihazı ile belirlenmiştir (Lindsay ve Norvell, 1978). Çalışma alanı topraklarında yapılan analiz sonuçlarına ilişkin bulgular Çizelge 2'den yararlanılarak değerlendirilmiştir. Agregat stabilitesi, sslak eleme yöntemiyle (Kemper ve Koch, 1966); plastiklik sınırı, yumuşak çamuru ip oluşuncaya kadar elle yuvarlama işlemi ile (Sayın, 1981); sıvılık sınırı, Casagranda aleti ile (Sayın, 1981) ve plastik indeksi, sıvılık sınırı ile plastiklik sınırı arasındaki nem fark1 hesaplaması (Sayın, 1981) ile yapılmıştır. Araştırılan elementler arasındaki ilişkiler Pearson korelasyon katsayısı ile SPSS programında (IBM SPSS Advanced Statistics version 19.0.0) analiz edilmiştir. 


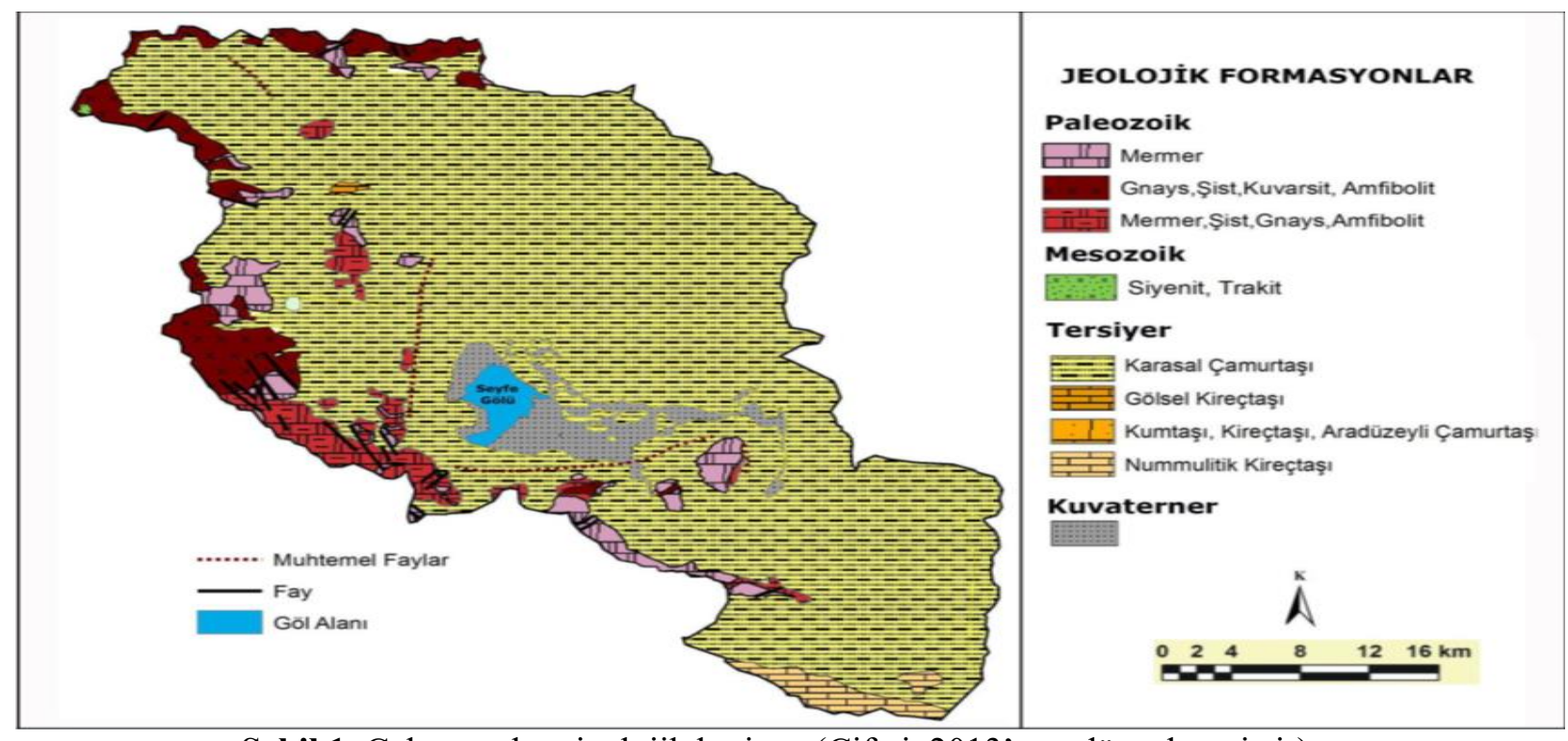

Şekil 1. Çalışma alanı jeolojik haritası (Çiftçi, 2013’ ten düzenlenmiştir)

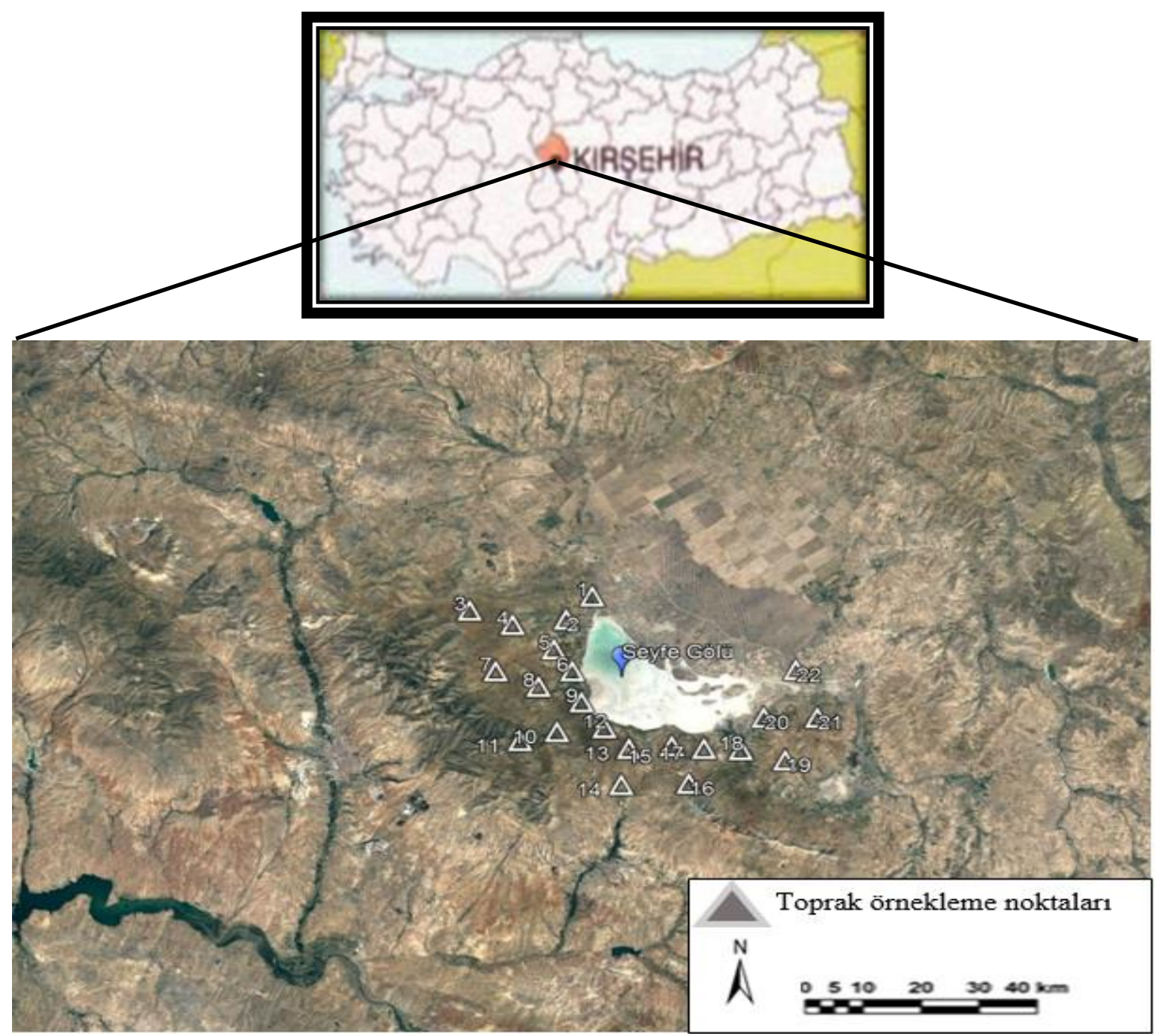

Şekil 2. Toprak örneği alınan noktalarla birlikte Seyfe Gölü sulak alan 
Çizelge 2. Toprakların bazı fiziksel ve kimyasal özellikleri ile besin elementi içeriklerini yorumlamaya ilişkin sınır değerleri

\begin{tabular}{|c|c|c|c|c|c|c|}
\hline \multirow[t]{2}{*}{ Besin maddesi } & \multirow[b]{2}{*}{ Çok az } & \multicolumn{3}{|c|}{ Yeterlilik Sınıfi } & & \multirow[t]{2}{*}{ Kaynak } \\
\hline & & $\mathrm{Az}$ & Yeterli & Fazla & Çok Fazla & \\
\hline Yarayışlı P $\left(\mathrm{mg} \mathrm{kg}^{-1}\right)$ & $<2.5$ & $2.5-8$ & $8-25$ & $25-80$ & $80<$ & Silanpää, 1990 \\
\hline Alınabilir K $\left(\mathrm{mg} \mathrm{kg}^{-1}\right)$ & $<50$ & $50-140$ & $140-370$ & $370-1000$ & $>1000$ & $\begin{array}{l}\text { Sumner and Miller, } \\
1996\end{array}$ \\
\hline Alınabilir Ca $\left(\mathrm{mg} \mathrm{kg}^{-1}\right)$ & $<380$ & $380-1150$ & $1150-3500$ & $3500-10000$ & $>10000$ & $\begin{array}{l}\text { Sumner and Miller, } \\
1996\end{array}$ \\
\hline Alınabilir $\mathrm{Mg}\left(\mathrm{mg} \mathrm{kg}^{-1}\right)$ & $<50$ & $50-160$ & $160-480$ & $480-1500$ & $>1500$ & $\begin{array}{l}\text { Sumner and Miller, } \\
1996\end{array}$ \\
\hline Alınabilir Mn ( $\left.\mathrm{mg} \mathrm{kg}^{-1}\right)$ & $<4$ & 4-14 & $14-50$ & $50-170$ & $170<$ & Silanpää, 1990 \\
\hline Alınabilir $\mathrm{Zn}\left(\mathrm{mg} \mathrm{kg}^{-1}\right)$ & $<0.2$ & $0.2-0.7$ & $0.7-2.4$ & $2.4-8.0$ & $8.0<$ & Silanpää, 1990 \\
\hline Alınabilir Fe $\left(\mathrm{mg} \mathrm{kg}^{-1}\right)$ & $\frac{\mathrm{Az}}{<2.5}$ & $\frac{\text { Orta }}{2.5-4.5}$ & $\frac{\text { Fazla }}{>4.5}$ & & & $\begin{array}{l}\text { Lindsay and } \\
\text { Norwell, } 1978\end{array}$ \\
\hline Alınabilir $\mathrm{Cu}\left(\mathrm{mg} \mathrm{kg}^{-1}\right)$ & $\frac{\text { Yetersiz }}{<0.2}$ & $\frac{\text { Yeterli }}{0.2<}$ & & & & Follet, 1969 \\
\hline Kireç $\left(\mathrm{g} \mathrm{kg}^{-1}\right)$ & $\frac{\text { Cok Az }}{<10}$ & $\frac{\text { Az Kireçli }}{10-50}$ & $\frac{\text { Orta Kireçli }}{50-150}$ & $\frac{\text { Fazla }}{150-250}$ & $\frac{\text { Çok Fazla }}{250<}$ & $\begin{array}{l}\text { Ülgen ve Yurtsever, } \\
1974\end{array}$ \\
\hline Organik madde $\left(\mathrm{g} \mathrm{kg}^{-1}\right)$ & $\frac{\text { Cok az }}{<10}$ & $\frac{\mathrm{Az}}{10-20}$ & $\frac{\text { Orta }}{20-30}$ & $\frac{\text { Iyi }}{30-40}$ & $\begin{array}{l}\text { Yüksek } \\
40<\end{array}$ & $\begin{array}{l}\text { Ülgen ve Yurtsever, } \\
1974\end{array}$ \\
\hline $\mathrm{EC}\left(\mathrm{dS} \mathrm{m}{ }^{-1}\right)$ & $\frac{\text { Tuzsuz }}{0-4}$ & Hafif tuzlu & $\begin{array}{l}\text { Orta tuzlu } \\
8-15 \\
\end{array}$ & $\frac{\text { Tuzlu }}{15<}$ & & Maas, 1986 \\
\hline $\mathrm{pH}$ & $\frac{\text { Orta asit }}{4.5-5.5}$ & $\frac{\text { Hafif asit }}{5.5-6.5}$ & $\frac{\text { Nötr }}{6.5-7.5}$ & $\frac{\text { Hafif alkalin }}{7.5-8.5}$ & $\frac{\text { Kuvvetli alkalin }}{8.5<}$ & Richards, 1954 \\
\hline
\end{tabular}

\section{Bulgular}

Araştırma konusu toprak örnekleri üzerinde yapılan bazı fiziksel ve kimyasal analiz sonuçları Çizelge 3'te verilmiştir. Çizelge 3 incelendiğinde; toprakların agregat stabilitesi oldukça değişkenlik göstermiş \% 13.5775.89 arasında değişmiştir. Toprakların plastiklik sınırı \% 20.12-33.8, sıvılaşma sınırı $\%$ 22.28-46.64 ve plastik indeksi \% 2.1619.97 arasında değişmiştir. Araştırma alanı topraklarının kum oranının \% 42.81-83.12, silt oranının \% 3.41-39.32 ve kil oranının \% 5.46-51.48 arasında oldukça değişken olduğu görülmüştür (Çizelge 3). Kum içeriğinde gölden uzaklaştıkça artış, kil yüzdesi göle yaklaştıkça yüksek bulunmuştur. Bünye analizi sonucunda alanın yaklaşık \% 90'ında kum oranı yüksek düzeylerde gözlenirken, bunu kil oranı takip etmiştir. Topraklarının saturasyon oran1 \% 41.28-95.28 arasinda değişkenlik göstermiştir. $\mathrm{pH}$ değerleri 7.318.53 arasında değişmekte olup alan topraklarının \% 4.5' inin $\mathrm{pH}$ 's1 kuvvetli alkalin iken geri kalanı hafif alkalin özelliktedir. EC değerleri 0.18-40.90 dS m ${ }^{-1}$ arasında değişmekte olup alanın \% 82'si çok tuzlu özelliktedir. Toprakların $\mathrm{CaCO}_{3}$ içerikleri oldukça değişken olup 64.24$691.95 \mathrm{~g} \mathrm{~kg}^{-1}$ (orta kireçli-çok fazla kireçli) arasında değişmektedir. Alanın yaklaşık \% 95'inde çok fazla kireçli toprakların hakim olduğu belirlenmiştir. Karasal ve denizel havzalar içerisinde ortak olarak oluşabilen en yaygın minerallerin, kireçtaşı $\left(\mathrm{CaCO}_{3}\right)$, jips $\left(\mathrm{CaSO}_{4} \cdot 2 \mathrm{H}_{2} \mathrm{O}\right)$, anhidrit $\left(\mathrm{CaSO}_{4}\right)$ ve halit $(\mathrm{NaCl})$ olduğu, Seyfe Gölü çevresinde metamorfik ve karbonat kayaların bulunduğu, drenajının yetersizliği, alanının kapalı hidrolojik sistemle çevrili olduğu ve tuzluluk oranındaki fazlalığı, kalsit ve jips minerallerinin birbirlerinin yerini alabildiği bildirilmiştir (Önalgil, 2013). Genel olarak toprakların yaklaşık \% 50'sinde az düzeyde organik madde saptanmış ve organik madde içerikleri 10.93-38.28 $\mathrm{g} \mathrm{kg}^{-1}$ (az-iyi) arasında değişmiştir.

Araştırma alanı topraklarının makroelement ve mikroelement içerikleri Çizelge 4'te 
verilmiştir. Çizelge 4 incelendiğinde; fosfor 90 'nn üzerinde olup bunları potasyum (166.6içerikleri 15.31-40.75 mg kg-1 (yeterli-fazla) $411.8 \mathrm{mg} \mathrm{kg}^{-1}$ ) ve magnezyum (72.1-851.1 olarak tespit edilmiştir. Alanın yaklaşık $\mathrm{mg} \mathrm{kg}^{-1}$ ) takip etmiştir. Araştırma alanı \%32'sinde yeterli ve \%68'inde fazla düzeyde topraklarında elverişli bakır yeterli $(0.23$ fosfor bulunmuştur. Değişebilir katyonlar $\left.2.56 \mathrm{mg} \mathrm{kg}^{-1}\right)$, mangan (1.05-10.58 mg kg-1), içerisinde sodyum (360.6-30486.3 mg kg-1) çinko (0.13-0.96 $\left.\mathrm{mg} \mathrm{kg}^{-1}\right)$ ve demir (0.05ve kalsiyum (3797.2-17920.1 $\mathrm{mg} \mathrm{kg}^{-1}$ ) baskın $1.20 \mathrm{mg} \mathrm{kg}^{-1}$ ) elementlerinin az olduğu tespit düzeydedir. $\mathrm{Bu}$ katyonların topraklardaki edilmiştir (Çizelge 4).

değişebilir katyonlar içerisindeki oranı \% 


\begin{tabular}{|c|c|c|c|c|c|c|c|c|c|c|c|c|}
\hline \multirow{2}{*}{$\begin{array}{c}\text { Toprak } \\
\text { No }\end{array}$} & AS & PS & SS & PI & $\mathrm{S}$ & Sİ & $\mathrm{C}$ & Sat. & $\mathrm{pH}$ & $\mathrm{EC}$ & $\mathrm{CaCO}_{3}$ & $\mathrm{OM}$ \\
\hline & $\%$ & $\%$ & $\%$ & $\%$ & $\%$ & $\%$ & $\%$ & $\%$ & & $\mathrm{dS} \mathrm{m}^{-1}$ & $\mathrm{~g} \mathrm{~kg}^{-1}$ & $\mathrm{~g} \mathrm{~kg}^{-1}$ \\
\hline 1 & 36.94 & 26.07 & 41.02 & 14.95 & 47.63 & 20.72 & 31.65 & 88.25 & 8.16 & 17.56 & 470.67 & 14.19 \\
\hline 2 & 13.57 & 25.55 & 40.27 & 14.72 & 48.05 & 14.04 & 37.91 & 90.03 & 7.31 & 15.28 & 559.78 & 24.35 \\
\hline 3 & 30.02 & 26.32 & 46.29 & 19.97 & 50.11 & 20.57 & 29.31 & 93.28 & 8.17 & 13.35 & 622.06 & 16.27 \\
\hline 4 & 31.23 & 24.78 & 40.33 & 15.55 & 51.90 & 16.76 & 31.33 & 95.28 & 8.21 & 11.03 & 569.30 & 19.76 \\
\hline 5 & 36.26 & 25.89 & 32.48 & 6.59 & 47.92 & 17.03 & 35.04 & 84.28 & 8.26 & 25.70 & 455.56 & 15.36 \\
\hline 6 & 41.91 & 24.52 & 31.62 & 7.10 & 49.24 & 16.91 & 33.84 & 91.03 & 8.31 & 23.50 & 572.67 & 16.32 \\
\hline 7 & 29.63 & 24.63 & 38.54 & 13.91 & 42.81 & 19.06 & 38.12 & 84.28 & 8.37 & 25.40 & 517.07 & 16.93 \\
\hline 8 & 49.94 & 24.53 & 29.29 & 4.75 & 49.98 & 19.33 & 30.69 & 65.03 & 8.23 & 34.80 & 570.76 & 20.26 \\
\hline 9 & 31.74 & 23.24 & 33.17 & 9.93 & 46.17 & 10.06 & 43.77 & 66.28 & 8.19 & 14.30 & 640.92 & 21.03 \\
\hline 10 & 32.83 & 22.86 & 35.38 & 12.52 & 48.41 & 7.90 & 43.69 & 68.03 & 8.27 & 16.02 & 615.22 & 19.76 \\
\hline 11 & 33.46 & 24.35 & 39.21 & 14.86 & 42.84 & 21.38 & 35.78 & 95.03 & 8.25 & 12.30 & 596.81 & 21.34 \\
\hline 12 & 25.62 & 26.71 & 44.20 & 17.49 & 45.16 & 3.41 & 51.42 & 84.28 & 8.44 & 7.12 & 690.50 & 16.94 \\
\hline 13 & 35.06 & 24.01 & 42.39 & 18.38 & 44.71 & 3.82 & 51.48 & 91.28 & 8.42 & 7.99 & 691.95 & 20.72 \\
\hline 14 & 29.69 & 25.87 & 37.44 & 11.57 & 48.87 & 12.22 & 38.92 & 73.03 & 8.14 & 13.15 & 688.59 & 26.04 \\
\hline 15 & 36.62 & 26.12 & 38.43 & 12.30 & 54.35 & 27.02 & 18.63 & 64.03 & 7.81 & 8.09 & 459.38 & 24.72 \\
\hline 16 & 58.85 & 25.14 & 38.45 & 13.31 & 57.96 & 9.53 & 32.46 & 70.28 & 8.39 & 0.463 & 619.15 & 12.53 \\
\hline 17 & 17.38 & 21.61 & 34.62 & 13.01 & 55.12 & 14.24 & 30.63 & 89.28 & 8.33 & 21.20 & 422.87 & 10.93 \\
\hline 18 & 18.19 & 25.16 & 29.17 & 4.01 & 52.84 & 26.25 & 20.92 & 92.28 & 8.53 & 36.20 & 601.91 & 20.26 \\
\hline 19 & 30.81 & 30.36 & 45.86 & 15.50 & 55.21 & 39.32 & 5.46 & 74.28 & 8.00 & 40.90 & 457.85 & 34.06 \\
\hline 20 & 75.89 & 33.80 & 46.64 & 12.85 & 55.76 & 17.87 & 26.37 & 65.28 & 7.83 & 0.93 & 341.66 & 38.28 \\
\hline 21 & 66.98 & 20.12 & 22.28 & 2.16 & 83.12 & 11.39 & 5.49 & 41.28 & 8.04 & 0.18 & 64.24 & 13.17 \\
\hline 22 & 43.21 & 26.56 & 40.57 & 14.01 & 62.25 & 14.39 & 23.35 & 63.28 & 7.71 & 0.44 & 139.23 & 28.60 \\
\hline Minimum & 13.57 & 20.12 & 22.28 & 2.16 & 42.81 & 3.41 & 5.46 & 41.28 & 7.31 & 0.18 & 64.24 & 10.93 \\
\hline Maksimum & 75.89 & 33.80 & 46.64 & 19.97 & 83.12 & 39.32 & 51.48 & 95.28 & 8.53 & 40.90 & 691.95 & 38.28 \\
\hline Ortalama & 36.62 & 25.37 & 37.62 & 12.25 & 51.84 & 16.51 & 31.65 & 78.59 & 8.20 & 15.72 & 516.63 & 20.54 \\
\hline Varyans & 229.6 & 7.42 & 37.35 & 21.63 & 71.64 & 63.12 & 139.6 & 199.1 & 0.043 & 133.55 & 26098 & 44.97 \\
\hline Std. sapma & 15.1 & 2.72 & 6.11 & 4.65 & 8.46 & 7.94 & 11.8 & 14.1 & 0.20 & 11.5 & 161 & 6.70 \\
\hline Çarpıklık & 1.04 & 1.20 & -0.602 & -0.661 & 2.30 & 0.82 & -0.589 & -0.77 & -0.869 & 0.574 & -1.512 & 1.039 \\
\hline Basıklık & 0.94 & 1.27 & 0.132 & -0.244 & 2.15 & 1.60 & 0.459 & 0.11 & 0.201 & -0.338 & 2.02 & 0.932 \\
\hline
\end{tabular}


Orta Kızılırmak Bölümündeki Seyfe Gölü Sulak Alanında Oluşan Toprakların Bazı Özelliklerinin İncelenmesi

\begin{tabular}{|c|c|c|c|c|c|c|c|c|c|}
\hline \multirow[t]{2}{*}{ Toprak No } & \multicolumn{5}{|c|}{ Toprakta makro elementler } & \multicolumn{4}{|c|}{ Toprakta mikro elementler } \\
\hline & $P$ & K & $\mathrm{Ca}$ & $\mathrm{Mg}$ & $\mathrm{Na}$ & $\mathrm{Cu}$ & $\mathrm{Zn}$ & $\mathrm{Mn}$ & $\mathrm{Fe}$ \\
\hline & $\mathrm{mg} \mathrm{kg}^{-1}$ & $\mathrm{mg} \mathrm{kg}^{-1}$ & $\mathrm{mg} \mathrm{kg}^{-1}$ & $\mathrm{mg} \mathrm{kg}^{-1}$ & $\mathrm{mg} \mathrm{kg}^{-1}$ & $\mathrm{mg} \mathrm{kg}^{-1}$ & $\mathrm{mg} \mathrm{kg}^{-1}$ & $\mathrm{mg} \mathrm{kg}^{-1}$ & $\mathrm{mg} \mathrm{kg}^{-1}$ \\
\hline 1 & 19.4 & 1900.2 & 4433.7 & 81.0 & 10703.7 & 1.46 & 0.31 & 3.35 & 0.31 \\
\hline 2 & 24.0 & 2030.9 & 4070.2 & 72.1 & 10880.5 & 1.26 & 0.16 & 1.72 & 0.30 \\
\hline 3 & 24.5 & 1943.9 & 7072.9 & 73.1 & 10122.5 & 1.90 & 0.25 & 2.50 & 0.28 \\
\hline 4 & 16.7 & 1682.5 & 8711.8 & 111.7 & 14666.5 & 1.27 & 0.15 & 1.79 & 0.26 \\
\hline 5 & 21.3 & 2205.0 & 4616.2 & 140.7 & 18556.5 & 1.22 & 0.15 & 1.74 & 0.27 \\
\hline 6 & 29.5 & 1813.3 & 4680.3 & 154.1 & 21466.5 & 1.19 & 0.22 & 1.08 & 0.78 \\
\hline 7 & 29.3 & 1856.6 & 6071.9 & 137.8 & 15877.2 & 1.48 & 0.26 & 1.41 & 0.46 \\
\hline 8 & 30.3 & 1769.5 & 4889.1 & 149.2 & 17486.5 & 1.23 & 0.17 & 1.41 & 0.40 \\
\hline 9 & 39.6 & 1291.1 & 4252.3 & 105.1 & 11786.5 & 1.22 & 0.13 & 1.75 & 0.30 \\
\hline 10 & 40.7 & 1117.1 & 4980.4 & 112.6 & 13766.5 & 0.89 & 0.14 & 1.55 & 0.46 \\
\hline 11 & 22.3 & 769.0 & 7163.9 & 106.6 & 9537.3 & 0.50 & 0.17 & 1.27 & 0.07 \\
\hline 12 & 28.9 & 812.4 & 3797.2 & 72.7 & 6100.6 & 0.49 & 0.18 & 2.52 & 0.37 \\
\hline 13 & 18.9 & 725.4 & 4434.5 & 87.6 & 6465.0 & 0.23 & 0.15 & 2.32 & 0.23 \\
\hline 14 & 25.6 & 986.6 & 5616.8 & 101.7 & 9807.5 & 0.67 & 0.20 & 2.25 & 0.17 \\
\hline 15 & 16.6 & 2466.0 & 7528.1 & 851.1 & 3390.6 & 1.03 & 0.58 & 9.13 & 0.05 \\
\hline 16 & 15.3 & 1247.5 & 5526.4 & 688.7 & 1065.6 & 0.73 & 0.25 & 4.19 & 0.23 \\
\hline 17 & 24.4 & 1726.6 & 8074.6 & 134.4 & 14697.6 & 1.17 & 0.25 & 1.05 & 0.39 \\
\hline 18 & 30.6 & 2640.1 & 9075.9 & 218.4 & 30486.3 & 1.52 & 0.44 & 1.14 & 0.64 \\
\hline 19 & 27.7 & 1204.6 & 17920.1 & 163.6 & 22231.8 & 1.19 & 0.47 & 1.41 & 0.25 \\
\hline 20 & 38.7 & 4118.8 & 5882.9 & 109.3 & 1104.5 & 1.62 & 0.96 & 10.58 & 0.09 \\
\hline 21 & 27.3 & 166.6 & 4252.1 & 93.0 & 360.6 & 2.56 & 0.74 & 5.76 & 1.20 \\
\hline 22 & 24.3 & 496.9 & 9985.8 & 242.6 & 4532.4 & 1.42 & 0.39 & 7.42 & 0.32 \\
\hline Minimum & 15.31 & 166.6 & 3797.2 & 72.1 & 360.6 & 0.23 & 0.13 & 1.05 & 0.05 \\
\hline Maksimum & 40.75 & 411.8 & 17920.1 & 851.1 & 30486.3 & 2.56 & 0.96 & 10.58 & 1.20 \\
\hline Ortalama & 26.2 & 1589.6 & 6515.3 & 183.5 & 11595.1 & 1.19 & 0.30 & 3.06 & 0.36 \\
\hline Varyans & 50.24 & 717630 & 9456141 & 37828 & 569545 & 0.252 & 0.046 & 7.237 & 0.069 \\
\hline
\end{tabular}


Orta Kızılırmak Bölümündeki Seyfe Gölü Sulak Alanında Oluşan Toprakların Bazı Özelliklerinin İncelenmesi

$\begin{array}{cccccccccc}\text { Std. sapma } & 7.08 & 847.13 & 3075.08 & 194.49 & 7546.82 & 0.50 & 0.21 & 2.69 & 0.26 \\ \text { Çarpıklık } & 0.527 & 0.973 & 2.449 & 2.121 & 0.525 & 0.481 & 1.747 & 1.769 & 1.853 \\ \text { Basılılk } & -0.219 & 1.978 & 1.714 & 1.614 & 0.121 & 1.257 & 2.06 & 2.102 & 1.931\end{array}$

$\mathrm{P}=$ Yarayış̧ı fosfor, $\mathrm{K}=$ Değişebilir potasyum, $\mathrm{Ca}=$ Değişebilir kalsiyum, $\mathrm{Mg}=$ Değişebilir magnezyum, Na=Değişebilir sodyum, $\mathrm{Cu}=\mathrm{Elverişli}$ bakır, $\mathrm{Zn}=$ Elverişli çinko, $\mathrm{Mn}=$ Elverişli mangan, $\mathrm{Fe}=$ Elverişli demir 


\section{1. İstatistiki Analiz Sonuçları}

Araştırma konusu toprak örneklerinin korelasyon analiz sonuçları Çizelge 5'te verilmiştir. Yapılan istatistiki analizler sonucunda kum ile plastik indeksi, kireç, EC arasında önemli negatif (r:-0.437**, r:$0.801^{* *}$, r: $\left.-0.359^{*}\right)$ ilişki bulunmuş, kil ile plastik indeksi, $\mathrm{pH}$ arasında önemli pozitif ilişki olduğu görülmüştür (r:0.371*, r:0.547**) (Çizelge 5). Araştırma alanı alüvyal, hidromorfik ve halomorfik topraklardan oluşmakta olup kumlu killi tın bünyelidir (Önalgil, 2013). Yapılan birçok çalışmada kum miktarının artmasıyla plastik indeksinde azalmanın olduğu belirtilmiştir (Gündüz ve Dağdeviren, 2009; Bektaş, 2012). Toprakların içermiş olduğu kil ve silt gibi fraksiyonların oranı ne kadar yüksekse plastik indeksi ve saturasyon yüzdeleri de doğrusal olarak yüksek nem ve yüksek su içeriklerinde oluşmaktadır (Abacı Bayan, 2016). Seyfe Gölü göl tabanı yüksek oranda tuz ve kireç içermekte olup yüksek kireç oranına sahip alanlarda iri kum ve iri çakıl boyutunda malzemeler önemli yer tutmaktadır (Sayhan, 2001). Yapılan bir araştırmada, Seyfe Gölü'nde siltli-tın, killitın ve tın tekstür sınıflarında üç farklı bünyenin yer aldığı, genellikle organik madde içeriğinin düşük, tuzluluğun çok şiddetli, pH'nın hafif alkalin, kireç oranının yüksek olduğu kaydedilmiştir (Çeşmeci, 2010).

Yapılan istatistiki analizler sonucunda plastiklik sınırı ile organik madde arasında önemli pozitif ilişki (r:0.765**), sıvılık sınırı ile saturasyon, organik madde arasında pozitif ilişki (r:0.356*, r:0.469**), plastik indeksiyle kil oranı, sıvılaşma sınırı, plastik sınırı arasında önemli pozitif ilişki (r:0.371*, r:0.907**, r:0.327*) bulunmuştur. Araştırma alanının bozunuma uğraması, organik maddenin düşük oluşu, atterberg sınırı olarak bilinen plastiklik, sıvılaşma sınırı ve plastik indeksi değerlerinin düşük olmasına neden olmakta, kıvam limitleri toprakların organik maddesi ve kil yüzdesi tarafından önemli düzeyde etkilenmektedir. Cassagrande (1936)'nın yaptığı sınıflandırma dikkate alınmış ve organik maddenin düşük olduğu topraklarda plastik sınırının düşük, plastikliğin düşük olduğu topraklarda da S1vı sınırının ve sıkışabilirliliğinin azaldığ görülmüştür (Sayın, 1981). Yapılan birçok çalışmada benzer bulgular kaydedilmiştir (Başkan, 2004; Bery ve Saad, 2012; Abac1Bayan, 2016).

Yapılan istatistiki analizler sonucunda $\mathrm{pH}$ ile toplam kireç arasında önemli pozitif ilişki (r:0.663**) bulunmuştur (Çizelge 5). Yılmaz (1990), Harran Ovasındaki yağış miktarının (350-500 mm) az olması ve toprağın yüksek miktarda kireç içeriğine sahip olmasından dolayı, toprağın alkali $\mathrm{pH}$ değerinde olduğunu belirtmiştir. Yapılan istatistiki analizler sonucunda toplam tuzluluk ile $\mathrm{pH}$, değişebilir $\mathrm{Na}, \mathrm{Ca}$ arasında önemli pozitif ilişki (r:0.429**, r:0.952**, r:0.386**) bulunmuştur (Çizelge 5). Çalışma alanı havzasındaki yeraltı suyu tuzluluğunun ve hidro-kimyasal fasiyelerinin oluşumunun ana nedeni Kizılirmak formasyonunun heterojenliği ve litojenik kirliliği, üst toprak bölgelerinin tuzluluğu, atmosfere açık kanal sularının buharlaşmasıdır (Çelik vd., 2007). Özellikle kurak devrede buharlaşmaya bağlı olarak oldukça kalın tuz katmanları geniş alana yayılmakta, tuz kabuklarının yayılış gösterdikleri alanlarda zemin son derece yumuşak olmakta ve tuzlu alkali topraklar yayılış göstermektedir ve aynı zamanda bu alan hidromorfik alüvyal toprakların yayılış sahasıdır (Sayhan, 2001). 
Orta Kızılırmak Bölümündeki Seyfe Gölü Sulak Alanında Oluşan Toprakların Bazı Özelliklerinin İncelenmesi

Çizelge 5. Seyfe Gölü sulak alan topraklarının bazı fiziksel ve kimyasal özellikleri arasındaki korelasyon matrisi

\begin{tabular}{|c|c|c|c|c|c|c|c|c|c|c|c|c|c|c|c|c|c|c|c|c|}
\hline & Kum & Kil & Silt & AS & SS & PS & $\mathrm{Pi}$ & Sat. & $E C$ & $\mathrm{pH}$ & $\mathrm{CaCO}_{3}$ & $\mathrm{OM}$ & $\mathrm{Cu}$ & $\mathrm{Mn}$ & $\mathrm{Zn}$ & $\mathrm{Fe}$ & $\mathrm{Mg}$ & $\mathrm{Na}$ & K & $\mathrm{Ca}$ \\
\hline Kil &,$- 741^{* *}$ & & & & & & & & & & & & & & & & & & & \\
\hline Silt & ,036 &,$- 698^{* *}$ & & & & & & & & & & & & & & & & & & \\
\hline AS &, $545^{* *}$ & $-327^{*}$ & - & & & & & & & & & & & & & & & & & \\
\hline ss &,$- 407^{* *}$ & 209 & 122 & -120 & & & & & & & & & & & & & & & & \\
\hline PS & 165 & 164 & , 420** & 240 & ,695** & & & & & & & & & & & & & & & \\
\hline Pi &,$- 437^{* *}$ & ,371* & -,086 &,$- 298^{*}$ & , $907^{* * *}$ & ,327* & & & & & & & & & & & & & & \\
\hline Sat. &,$- 692^{* *}$ & ,434** & 092 &,$- 645^{* *}$ & ,356* & 035 & , $447^{* *}$ & & & & & & & & & & & & & \\
\hline EC &,$- 359^{*}$ & 137 & ,586** &,$- 521^{* *}$ & 192 & 003 & - 254 & , 474** & & & & & & & & & & & & \\
\hline $\mathrm{pH}$ &,$- 458^{* *}$ &, $547^{* *}$ &,$- 325 *$ &,$- 464^{* *}$ & 位, &,$- 429 * *$ & - -028 & ,584** &, $429 * *$ & & & & & & & & & & & \\
\hline $\mathrm{CaCO}_{3}$ &,$- 801^{* *}$ & ,694** & -179 &,$- 489 * *$ & 246 &,- 017 & ,333* & ,582** & 270 & ,663** & & & & & & & & & & \\
\hline OM & -,015 & -243 & ,378* & 185 & ,469** & ,765** & 168 &,- 230 & - &,$- 611^{* *}$ & 144 & & & & & & & & & \\
\hline $\mathrm{Cu}$ & ,644** &,$- 658^{* *}$ & 293 & ,321* &,$- 335 *$ & -,042 &,$- 416 * *$ &,$- 363^{*}$ & ,045 &,$- 351^{*}$ &,$- 678^{* *}$ & -,058 & & & & & & & & \\
\hline $\mathrm{Mn}$ & ,491** & -375* & ,034 & ,649** & ,207 & ,448** & ,010 &,$- 578^{* *}$ &,$- 663^{* *}$ &,$- 773^{* *}$ & -,581** & , 456** & 273 & & & & & & & \\
\hline $\mathrm{Zn}$ & ,644** &,$- 690^{* *}$ & ,340* &, $612^{* *}$ & 016 & ,446** & -241 &,$- 537^{* *}$ &,- 256 &,$- 616^{* *}$ &,$- 670^{* *}$ & ,463** & ,552** & , 782** & & & & & & \\
\hline $\mathrm{Fe}$ &, $544^{* *}$ & -293 & -143 & 156 &,$- 686 * *$ &,$- 517^{* *}$ &,$- 598^{* *}$ &,- 273 & 127 & 200 &,$- 376^{*}$ &,$- 423 * *$ &, $557^{* *}$ & 157 & 175 & & & & & \\
\hline Mg & 197 & -289 & 221 & 196 &,- 006 & ,071 &,- 050 & -288 &,- 230 & -251 & -,055 & 012 & -153 & , 458** & 224 & -244 & & & & \\
\hline $\mathrm{Na}$ & $-357^{*}$ &,- 061 & , 471 ** &,$- 536^{* *}$ & -261 & -,059 &,$- 308^{*}$ &, $477^{* *}$ & ,952** & ,446** & ,307* & -077 & 023 &,$- 690^{* *}$ &,$- 329^{*}$ & 178 & -267 & & & \\
\hline K & -202 & -110 & ,378* & 109, & 190 &, $573^{* *}$ &,- 086 & 183 & 243 & -110 & 041 & ,311* & 230 & ,306* & , 399** & -269 & 134 & 204 & & \\
\hline $\mathrm{Ca}$ & 159 &,$- 616^{* *}$ & , 746** & -,167 & ,305* & ,379* & 178 & ,042 & ,386** &,$- 334^{*}$ & -206 & ,468** & 072 & -,007 & 235 & -174 & 159 & , 353* & -,006 & \\
\hline P & -049 & 099 & -095 & 112 & -168 & 113 & -,287 &,$- 313^{*}$ & 123, & - -028 & 001 & ,306* & 202 & -035 & 177 & 248 &,$- 421^{* *}$ & 208 & 179, & -091 \\
\hline
\end{tabular}

$\left(^{*}=p<0.05\right.$ : İstatistiksel olarak anlamlı fark vardır, ${ }^{* *}=p<0.01$ : Yüksek düzeyde olarak anlamlı fark vardır) Sat.= Saturasyon yüzdesi, $E C=$ Toplam tuzluluk, CaCO ${ }_{3}=$ Toplam kireç, OM=Organik madde, $\mathrm{YP}=$ Yarayışlı fosfor, Değ. K= Değişebilir potasyum, Değ. Ca= Değişebilir kalsiyum, Değ. Mg= Değişebilir Magnezyum, Değ. Na= Değişebilir Sodyum, Albr. Fe= Yarayışılı demir, Albr. Mn= Yarayışılı mangan, Albr. Zn= Yarayışıı çinko, Albr. Cu= Yarayışlı bakır $(*=p<0.05, * *=p<0.01)$ 
Alanda artan tuz miktarı ile birlikte özellikle değişebilir sodyum oranı artmış ve benzer bulgular Jordan vd. (2004), Horneck vd. (2007) tarafından toprakta $\mathrm{Ca}$ ve $\mathrm{Na}$ gibi katyonların artmasiyla toprakta tuzluluğun meydana geldiği ve bu durumda EC değerinin arttı̆̆ rapor edilmiştir. Sarı vd. (2003), Manay Gölünün kurutulması ile kazanılan toprakların drenajının kötü ve değişebilir Na miktarının yüksek olduğunu belirtmişler, toprakta alkalilik ve tuzluluk sorunlarının olduğunu kaydetmişlerdir. Sütgibi (2009), Küçük Menderes Nehri Delta Ovasında yer altı sularının aşırı kullanımı sonucu tarım topraklarında tuzlanmanın olduğunu belirtmiştir.

Yarayışı ı fosforu fazla olan araştırma alanı topraklarında yüksek düzeydeki $\mathrm{Mg}$ ile aralarında negatif ilişki (r:-0.421**) olduğu ve toprak pH'sının bazik olduğu koşullarda yarayışlı fosfor düzeyinin etkilendiği tespit edilmiştir. Yüksek düzeydeki $\mathrm{Mg}$, toprak $\mathrm{pH}$ ' sının bazik olduğu koşullarda alınabilir fosfor düzeyini etkileyebilmektedir (Abacı Bayan, 2016). Effiong ve Ibia (2009) tarafindan Güneydoğu Nijerya'daki bazı taşkın nehirlerin yer aldı ̆̆ topraklar üzerinde yaptıkları araştırmada ve Yu vd. (2014)'nın Sarı Nehir deltası topraklarında yaptıkları araştırmada yarayışılı P ile Mg iyonu arasında negatif korelasyon olduğu rapor edilmiş, yüksek pH'nın etkili olduğu belirtilmiştir. Dökmeci (2005), Gala Gölü ve çevresi topraklarında $\mathrm{Mn}$ elementini diğer mikro elementlerden fazla oranda bulmuştur. Yapılan bu çalışmada da Mn elementinin diğer elementlere oranla yüksek olması literatürle desteklenmiştir. Okur vd. (2011), Gediz Deltası sulak alan topraklarının alkali reaksiyonlu, toplam çözünebilir tuz yönünden problemli olduğunu, en yüksek varyasyon değişkenliğini $\mathrm{Mn} \quad(\mathrm{vk}=32.61)$ elementinin gösterdiğini bildirmişlerdir.

\section{Sonuç}

$\mathrm{Bu}$ çalışmada, Orta Anadolu'nun Orta Kızılırmak Bölümünde bulunan A sinıfı sulak alanı olan Seyfe Gölü üzerinde yapılan uygulamalar sonucu ortaya çıkan topraktaki bazı özellikler belirlenmiştir. Kurak ve yarı kurak bölge topraklarında oksidasyon koşulları y1lın önemli bir kısmında etkili olduğundan organik madde düzeyi düşük bulunmuştur. Alanda kapalı hidrolojik bir sistemin olması ile havzada tuzluluk oran1 yükselmiş ve yağışa bağlı olarak toprak yüzeyinde kalsik formun oluştuğu görülmüştür. Yağışın az olması ve toprağın yüksek kireç ve $\mathrm{Na}$ içeriğine sahip olmasından dolayı toprağın alkali $\mathrm{pH}$ değerinde olduğu belirlenmiştir. Araştırma alanı topraklarında değişebilir katyonlar arasinda $\mathrm{Na}$ baskin olarak bulunurken bunu sırasıyla $\mathrm{Ca}, \mathrm{K}$ ve $\mathrm{Mg}$ takip etmiştir. Değişebilir kalsiyumun yüksek düzeylerdeki tespiti sedimenter kayaçlar içerisinde yer alan kalsiyumca zengin kireç taşının bölgede yaygın olarak bulunması ve alanda toplam $\mathrm{CaCO}_{3}$ içeriğinin fazla olmasından kaynaklanabilir. Alanda drenajın kötü olması ve yeterli yağışın olmadığı iklim koşullarında $\mathrm{Ca}$ ve $\mathrm{Na}$ elementinin birikimi beklenebilir sonuçtur. Çalışma alanı topraklarının yarayışlı $\mathrm{Zn}, \mathrm{Mn}$ ve Fe düzeylerinin düşük, topraktaki hareketi sınırlı olan $\mathrm{Cu}$ düzeyinin yeterli seviyede olduğu tespit edilmiştir.

Seyfe Gölü’nün kapalı havza içerisinde bulunması, drenajının yetersiz olması, yüzey topraklarında organik maddenin düşük, kirecin ve tuzluluğun yüksek, toprak alkaliliği açısından sorun yaratan sodyumun yüksek oranlarda bulunması ve pH'nın 8'in üzerinde olması araştırma alanının ileriye dönük hem alkalilik hem de tuzluluk yönünden takip edilmesi gerektiği sonucuna varılmıştır. Açık ve kapalı drenaj 
sistemlerinin kurulması ile drenaj sağlanmalı, uygun su idaresinin yapılması ve yıkama işleminin yapılması gibi ıslah yöntemleri gerçekleştirilebilmelidir.

\section{Teşekkür}

$\mathrm{Bu}$ çalışma, Kırşehir Ahi Evran Üniversitesi Bilimsel Araştırma Projesi (Proje No: BAP ZRT.A3.17.004) tarafından desteklenmiştir. Proje analizlerinin yapımı Kırşehir Ahi Evran Üniversitesi Merkezi Uygulama ve Araştırma Laboratuvarında gerçekleştirilmiştir.

\section{KAYNAKLAR}

Abac1-Bayan, A.A. 2016. Doğu Akdeniz Bölgesinde Yer Alan Sulak Alanlarda Oluşan Toprakların Özellikleri, Verimlilik Düzeyleri Ve Sorunları. Kahramanmaraş Sütçü İmam Üniversitesi, Fen Bilimleri Ens. Toprak Bilimi ve Bitki Besleme Anabilim dalı. Doktora tezi, 271 ss.

Anonim, 2014. Sulak alanların korunmas1 yönetmeliği.https://www.resmigazete.gov.tr/eskil er/2014/04/20140404-11.htm.

Başkan, O. 2004. Gölbaşı Yöresi Topraklarının Mühendislik-Fiziksel Özellik İlişkilerinde Jeoistatistik Uygulaması. Doktora Tezi. Ankara Üniversitesi Fen Bilimleri Enstitüsü Toprak Anabilim Dalı. 188 ss.

Bektaş, A.R. 2012. Erzurum-Tekman Yöresinde Farklı Arazi Kullanımı Altındaki Toprakların Bazı Fiziksel, Kimyasal ve Mekaniksel Özellikleri Üzerine Bir Araştırma. Yüksek Lisans Tezi. Atatürk Üniversitesi Fen Bilimleri Enstitüsü Toprak Bilimi ve Bitki Besleme Anabilim Dalı. 56 ss.

Bery, A.A. and Saad, R. 2012.Tropical Clayey Sand Soil's Behaviour Analysis and Its Empirical Correlations via Geophysics Electrical Resistivity Method and Engineering Soil Characterizations. International Journal of Geosciences, 3 (1): 111116.

Black, C.A. 1965. Methods of Soil Analysis, Agronomy, No: 9, Part: 1 and 2. Agr., Madison, Wisc.,1572p.
Bouyocous, G.L. 1951. A Recalibration of Hydrometer Method for Making Mechanical Analysis of soils. Agron. J. 43:434-438.

Budak, M ve Günal, H. 2015. Tuzlu-Alkali Topraklarda Bor Konsantrasyonunun Uzaysal Değişkenliğinin Jeoistatistiksel Analizi ve Haritalanması. Ege Üniv. Ziraat Fak. Dergisi, 52 (2):191-200 ISSN 1018-8851.

Çelik, M and Yıldırım, T. 2006. Hydrochemical evaluation of groundwater quality in the Çavuşçayı basin, Sungurlu-Çorum, Turkey. Environmental Geology, 50:323-330.

Çelik, M. 2002. Water Quality assessment and the investigation of the relationship between the River Delice and the aquifer systems in the vicinity of Yerköy (Yozgat, Turkey). Environmental Geology, 42(6):690-700.

Çelik, M., Ünsal, N., Tüfenkçi, O ve Bolat, S. 2007. Assesment of water quality and pollution of the Lake Seyfe basin, Kırşehir, Turkey. Environmental Geology, 55: 559-569.

Çeşmeci, H. 2010. İklim Değişikliğinin Seyfe Gölü Sulak alanına, İklimine, Ekolojisine Ve Yöre Halkının Yaşamına Etkileri. Çanakkale Onsekiz Mart Üniv. Sosyal Bilimler Enst. Coğrafya Anabilim Dalı. Yüksek lisans tezi. 366 ss.

Çiftçi, E. 2013. Seyfe Gölü Havzası'nda (Kırşehir) Doğal Ortam-Yeraltı suyu İlişsisi. Fırat Üniversitesi Sosyal Bilimler Enstitüsü Coğrafya Anabilim Dalı. Yüksek Lisans Tezi. 124 ss.

Demiralay, İ. 1993. Toprak Fiziksel Analizleri. Atatürk Üniversitesi Ziraat Fakültesi Yayınları No: 143, ss: 131, Erzurum.

Dökmeci, A.H. 2005. Gala Gölü ve Gölü Besleyen su kaynaklarında ağır metal kirliliğinin araştırılması. Yüksek lisans tezi, Trakya Üniversitesi, Fen Bilimleri Enstitüsü, 122 ss.

Effiong, G.S. and Ibia, T.O. 2009. Characteristics and Constraints of Some River Flood Plains Soils to Crop Production in Southeastern Nigeria. Agricultural Journal 4 (2): 103-108.

Ekmekçi, E., Apan, M. ve Kara, T. 2005. Tuzluluğun Bitki Gelişimine Etkisi. OMÜ Ziraat Fak. Dergisi, 20(3):118-125.

Erdem, O. 2005. Onlar Ne Dedi? Seyfe Gölü, Gavur Gölü, Ereğli Sazlıkları, Eşmekaya Sazlıkları ve Avlan Gölü Nasıl Kurutuldu? Kuş Araştırmaları Derneği, Ankara. 
Erguvanl1, K. 1959. Hydrogeology of the Seyfe Plain in northern Kırşehir, Central Anatolia, Turkey. Institute of hydrogeology Technical University of Istanbul, Publication no. 4, Istanbul, $24 \mathrm{p}$.

Eyüboğlu, Ö. 1995. Seyfe Gölü (Kırşehir)Tabiatı Koruma Alanının Florası, Doktora Tezi, Gazi Üniversitesi, Fen Bilimleri Enstitüsü, Ankara.

Follet, R.H. 1969. $\mathrm{Zn}, \mathrm{Fe}, \mathrm{Mn}$ and $\mathrm{Cu}$ in Colorado Soils. Ph. D. Dissertation. Colorado State University.

Gülçur, F. 1974. Toprağın Fiziksel ve Kimyasal Analiz Metotları, İstanbul Üniversitesi Orman Fakültesi Yayınları, İ. Ü. Yayın No: 1970, O. F. Yayın No: 201, Kutulmuş Matbaası, İstanbul.

Gündüz, Z. ve Dağdeviren, U. 2009. Zeminlerin Kıvam Limitlerinin Ölçümünde Ortamdaki Kumların Değerlendirmeye Etkileri. İMO Teknik Dergi, 20 (2): 4701-4715

Helmke, P.A. and Sparks, D.L. 1996. Lithium, Sodium, Potassium, Rubidium, and Calcium, in Sparks, D.L., (Ed) Methods of Soil Analysis, Part 3, Chemical Methods, SSSA Book Series Number 5, SSSA., Madison,WI, pp:551-574.

Horneck, D.A., Ellsworth, J.W., Hopkins, B.G., Sullivan, D.M. and Stevens, R.G. 2007. Managing Salt Affected Soils for Crop Production. A Pacific Northwest Extension. Oragen State University.

Jackson, M.L. 1962. Soil Chemical Analysis. Prentice-Hall Inc., 183.

Jordan, M.M., Pedreno, J.N., Sanchez, E.G., Mateu, J. and Juan, P. 2004. Spatial Dynamics of Soil Salinity Under Arid and Semi-Arid Conditions: Geological and Environmental Implications. Environmental Geology 45:448456.

Junk, W., Brown, Campbell, I.C., Finlayson, M., Gopal, B., Ramberg, L. and Warner, B.G. 2006. The comparative biodiversity of seven globally important wetlands: A synthesis. Aquatic science. 68:400-414.

Kanber, R., Çullu, M.A., Kendirli, B., Antepli, S. ve Yilmaz, N. 2005. Sulama, Drenaj ve Tuzluluk.www.zmo.org.tr/etkinlikler/6tk05/013ri zakanber.pdf.

Kara, H. 1991. 1/100.000 ölçekli açınsama nitelikli Türkiye Jeoloji Haritası, Kırşehir paftası ve açıklaması. MTA Enstitüsü yayınları Ankara.
Karaoğlu, M. ve Yalçın, A.M. 2018. Toprak Tuzluluğu Ve Iğdır Ovası Örneği. Journal of Agriculture 1(1): 27-41.

Kemper, W.D. and Koch, E.J. 1966. Aggregate Stability of Soils From Western United States and Canada. U.S. Dept. Agriculture Tech. Bull No. 1355.

Lindsay, W.L. and Norvel, W.A. 1978. Development of DTPA Soil Test for Zn, Fe, Mn and $\mathrm{Cu}$. Soil Sci. Amer. J. 42(3):421-28.

Maas, E.V. 1986. Salt Tolerance of Plants. Applied Agricultural Research, 1:12-26.

Meteoroloji Genel Müdürlüğü, 2016. T.C. Tarım ve Orman Bakanlığı Meteoroloji Genel Müdürlüğü İklim parametrelerin analizi.

Moreno-Casasola, P., Rosas, H.L., Mata, D.I., Peralta, L.A., Travieso-Bello, A.C. and Warner, B.G. 2009. Environmental and Anthropogenic Factors Associated with Coastal Wetland Differentiation in La Mancha, Veracruz, Mexico. Plant Ecology. 200:37-52.

Nelson, D.W. and Sommers, L.E. 1996. Total Carbon, Organic Carbon, and Organic Matter. P: 9611011. In D.L. Sparks (ed) Method of Soil Analysis: Chemical Methods. Part 3. SSSA, Madison, WI.

Okur, B., Delibacak, S., Yağmur, B., Ongun, A.R. ve Ustaoğlu, R. 2011. Gediz Deltası Sulak Alan Topraklarının Bazı Fiziksel ve Kimyasal Özelliklerinin Belirlenmesi. II. Türkiye Sulak Alanlar Kongresi, 22-24 Haziran 2011, Kırşehir/TÜRKIYYE.96-105 ss.

Olsen, S.R., Cole, V., Watanabe, F.S. and Dean, L.A. 1954. Estimation of Available Phosphorus in Soils by Extraction With Sodium Bicarbonate, U.S.A.

Önalgil, N. 2013. Seyfe Gölü (Kırşehir) Güncel Çökellerinin Sedimantolojisi, Mineralojisi, Jeokimyası ve Oluşumu. Eskişehir Osmangazi Üniversitesi Fen Bilimleri Enstitüsü Yüksek Lisans Tezi Jeoloji Mühendisliği Anabilim Dalı. 95 ss.

Richards, L.A. 1954. Diagnosis and improvement of saline and alkali soils. United States Department of Agriculture Handbook, 60.

Sarı, M., Altunbaş, S. ve Yıldıran, M. 2000. Göller Yöresinde Kurutulan Kestel Göl Alanından Kazanılan Arazilerin Özelliklerinin Belirlenmesi Çevre Bakanlığı, Çevre Koruma Genel Müdürlüğü Araştırma Raporu, Ankara. 
Sarı, M., Altunbaş, S., Sönmez, N.K. ve Emrahoğlu, I. 2003. Farklı Fizyografik Üniteler Üzerinde Yer alan Eski Manay Göl Alanı Topraklarının Özellikleri Ve Potansiyel Üretkenlikleri. Akdeniz Üniversitesi Ziraat Fakültesi Dergisi 16: 7-17.

Sayhan, H. 2001. Seyfe Gölü eski seviyelerinin kuaterner jeomorfolojisi açısından etüdü. Gazi Üniversitesi Kırşehir Eğitim Fakültesi dergisi 2 (2): 55-73.

Sayın, M. 1981. Toprak Mekaniği Ders Notları. Çukurova Üniv. Ziraat Fak. Toprak Bölümü. Adana.

Seymen, İ. 1982. Geology of Kırşehir massive around kaman. $\mathrm{PhD}$ thesis, İstanbul Technical University, Mineral faculty, 164 pp (in Turkish).

Silanpää, M. 1990. Micronutrient assessment at country level: An international study. In: FAO Soils Bulletin. N.63. Rome.

Sumner, M.E. and Miller, W.P. 1996. Cation exchange capacity and exchange coefficients. In D.L. Sparks (ed.) Methods of soil analysis, Part 3. Chemical methods. Soil Science Society of America, Book series no. 5.

Sütgibi, S. 2009. Küçük Menderes Nehri Delta Ovası ve Degradasyonal Etkileri. Ege Coğrafya Dergisi, 18 (1-2): 59-72.

Türkeş M. 1996. Spatial and temporal analysis of annual rainfall variations in Turkey. International Journal of Climatology, 16, 1057-1076.

Türkeş, M. 2007. Orta Kızılırmak Bölümü güney kesiminin (Kapadokya Yöresi) iklimi ve çölleşmeden etkilenebilirliği (Climate of southern part of the Middle Kizılirmak Sub-Region (Cappadocia District) and its vulnerability to desertification). Ege Üniversitesi Coğrafya Dergisi 14: 75-99.

Tüzüner, A. 1990. Toprak ve Su Analiz Laboratuvarları El Kitabı. T.C. Tarım Orman ve Köy işleri Bakanlığı Köy Hizmetleri Genel Müdürlüğü. S.21-27.

Ülgen, N. ve Yurtsever, N. 1974. Türkiye gübreler ve gübreleme rehberi. Toprak ve Gübre Araştırma Enstitüsü Müdürlüğü, Teknik Yayınlar No:28. Ankara.

Y1lmaz, K. 1990. Harran Ovası Topraklarının Mineralojik Karakterizasyonları. Doktora Tezi. Ç. Ü. Fen Bilimleri Ens., Adana.
Yu, J., Qu, F., Wu, H., Meng, L., Du, S. and Xie, B. 2014. Modified Hedley fraction method was used to study the forms and profile distribution in the tidal river network region subjected to rapid deposition and hydrologic disturbance in the Yellow River Delta. The Scientific World Journal, pp.1-11.

Zor, M. ve Şengün, M.T. 2002. "Amik Ovasının Hidroğrafik Özelliklerinde Meydana Gelen Değişmeler ve Bunun Sonucunda Ortaya Çıkan Sorunlar", Su Havzalarında Toprak ve Su Kaynaklarının Korunması Geliştirilmesi ve Yönetimi Sempozyumu: 338-343, 18-20 Ekim 2002. Antakya/Hatay. 